\title{
The quality of caring relationships
}

\author{
Tineke A Abma \\ Barth Oeseburg \\ Guy AM Widdershoven \\ Marian Verkerk
}

Medical Humanities/EMGO Institute, VU Medical Center, Amsterdam, The Netherlands
Correspondence:Tineke A Abma Medical Humanities/EMGO Institute,VU Medical Center, Po Box 7057, 1007 MB Amsterdam, The Netherlands

$\mathrm{Tel}+3 \mid 43388$ I। 32

Fax +3I 204448218

Email t.abma@vumc.nl
Abstract: In health care, relationships between patients or disabled persons and professionals are at least co-constitutive for the quality of care. Many patients complain about the contacts and communication with caregivers and other professionals. From a care-ethical perspective a good patient-professional relationship requires a process of negotiation and shared understanding about mutual normative expectations. Mismatches between these expectations will lead to misunderstandings or conflicts. If caregivers listen to the narratives of identity of patients, and engage in a deliberative dialogue, they will better be able to attune their care to the needs of patients. We will illustrate this with the stories of three women with multiple sclerosis. Their narratives of identity differ from the narratives that caregivers and others use to understand and identify them. Since identities give rise to normative expectations in all three cases there is a conflict between what the women expect of their caregivers and vice-versa. These stories show that the quality of care, defined as doing the right thing, at the right time, in the right way, for the right person, is dependent on the quality of caring relationships.

Keywords: ethics of care, dialogue, responsibilities, narratives, relationships

\section{Introduction}

It is not uncommon that expectations between patients and their health care professionals' conflict. This creates tensions in the caring relationship. The purpose of this study is to understand these tensions from a care-ethical perspective. ${ }^{1-3}$ From a care-ethical perspective a good patient-professional relationship requires a process of negotiation and shared understanding about mutual normative expectations. ${ }^{4}$ Mismatches between these expectations will lead to misunderstandings or conflicts. If caregivers listen to the narratives of identity of patients, and engage in a deliberative dialogue they will better be able to attune their care to the needs of patients. ${ }^{5}$

We will illustrate this with the stories of three women with multiple sclerosis (MS): Ann, Kathy, and Jane (pseudonyms). MS is a chronic progressive neurological disease with profound effects on all facets of life: physical, cognitive, and emotional, work, social activities, financial status, and family functioning. ${ }^{6,7}$ Living with MS is a matter of balancing different and sometimes conflicting activities. Care for persons with a chronic disease like MS is complex and health care professionals are not always familiar with the disease and special needs of these patients. ${ }^{8}$ In the cases presented there is a clash of expectations which leads to tense relationships between the disabled women and their professionals.

This article consists of the following parts: We start off with sections on the theoretical framework and methodology. In the following sections, the stories of Ann, Kathy, and Jane will be presented. Their narratives illuminate the normative expectations towards themselves, others, and vice versa. In an analysis we will investigate how conflicting normative expectations are grounded in diverging narratives of identity. Finally, we will discuss how the findings can be used in helping health care professionals to build up caring relationships which are adjusted to the uniqueness of disabled persons. 


\section{A care-ethical perspective on relationships}

This study is based on Margaret Walker's expressivecollaborative view of morality. Walker ${ }^{2}$ describes morality as situated in social practices, which makes morality fundamentally interpersonal. Moral life is centered around relationships. People jointly construct and maintain moral orders through their interactions. This process takes place against a background of (moral) understandings about what people are supposed to do, expect, and understand. Walker states that these 'understandings' - ideas about who we are and how to handle various situations - are expressed through practices of responsibility.

Walker does not understand responsibility in legal terms, but redefines the concept of responsibility as 'whom I care about.' With the emphasis on care as a central element of responsibility, Walker's view of morality resonates with Joan Tronto's ${ }^{1}$ normative theory on the ethics of caring. Responsibility includes the notion of responding; listening, being attentive, and answering in response to the needs of others. Walker does, however, not describe when and what should be done by whom to whom. The specific interpretation of the question of who is responsible to whom, for what is context-bound, and depends on the particular circumstances and the people involved in the situation.

Commonly we speak about the 'division' of responsibilities. This implies a focus on the outcome of a negotiation process over who does what to whom. Walker rather concentrates on the process of negotiation over responsibilities between human actors when she talks about the assignment, acceptance, and deflection of responsibilities. Walker's moral-epistemology implies that the assignment of responsibilities is shaped and defined by normative, often moral expectations. These normative expectations are expressed in and at least partly constituted by narratives of identity.

Narratives of identity, as Walker ${ }^{2}$ understands them, are the complicated interactions of the first-person stories by which one makes sense of oneself and the third-person stories that others use to identify one. Often, the third-person stories are different from those that figure into one's self-conception and it is the clash between these different narratives of identity that creates tensions in the relationships between patients and their professionals.

\section{Multiple case study}

Since normative expectations are grounded in stories, we followed a multiple case study approach in our research on the division of responsibilities for chronically ill. The research team collected fifteen case stories from fifteen MS patients and one or two of their health care professionals $(n=24)$. We choose to have a mix of cases with regard to the stage of the illness (MS patients living at home with minimal disabilities; those going for a treatment to a rehabilitation center; severely disabled MS patients hospitalized within a nursing home). The case study ended when no more new insights were added to the existing data set ('saturation'). The cases were later used as input for two focus groups: one among MS patients and one among health care professionals.

In this article we present three cases. Although these cases represent the different stages of MS, they are selected primarily on our theoretical notions regarding normative expectations (theoretical sampling). The cases show how narratives of identity structure normative expectations, and how clashes between narratives of identity may lead to conflicting expectations. Ann perceives herself as being quite independent, yet vulnerable, and is still living at home. Kathy portrays herself as losing much of her independence and autonomy. She visits her general practitioner (GP) and a rehabilitation center to get support. Jane has always been quite critical and independent, but is now physically completely dependent on the nursing staff at the nursing home. All these women relate about their care givers and others who misunderstand their needs and expectations.

The interviews with the MS patients and their professional caregivers had the character of a 'natural' conversation structured by the issues coming up during conversation. ${ }^{9}$ The interviewer did not start with a list of predefined topics, but began with an open question. MS patients were asked what happened when they became ill and health care professionals were asked how they handled a specific care situation. The interviews lasted about two hours. The interviews were taperecorded, transcribed in their entirety, and analyzed following a narrative approach. ${ }^{10}$ Besides the content of the stories, the narrative structure and linguistic elements (discourse, metaphors) were addressed in the analysis. Metaphors convey the meaning of experiences. For example, Ann talks about work as being a 'holy grail.' The trouble she goes through finding work is like a 'crusade.' These concrete terms help us to understand how it feels when an ambitious person with a disability is unable finding a job. In Kathy's story we were struck by the use of the word 'loss.' Kathy labeled many experiences in terms of losing something (health, work, friends, family, etc); loss was thus considered to be a main theme in her life. The narrative structure illuminates the meaning endowed to the development of events over time. Whereas the narrative structure of Kathy's story is progressive (she lives happily 
after all that happened), Jane's account is clearly tragic and regressive. Ann's story plot is more ambiguous; it reads like a journey which goes back and forth, and progression and regression are iterating.

It is common within the qualitative research tradition to give respondents the opportunity to discuss one's findings and to see whether or not they recognize the interpretation made by the interpreter(s). This so-called 'member check' is a helpful procedure to check the credibility of one's findings. ${ }^{11}$ Ann and Kathy responded to and approved to our interpretation of their stories. In the case of Jane it was, however, not possible to get a response, given her bad condition. She preferred not to be consulted and died several months after the interview in a nursing home.

The credibility of the findings was also enhanced because the stories were analyzed by various members in the research team and discussed in team meetings. This strategy for verification is known as "inter-rated reliability. ${ }^{\text {"1 }}$ Furthermore, methodological choices were discussed with two independent senior researchers. This included discussions about the transformation of Walker's meta-ethical framework for the analysis of empirical data, the application of Walker's concepts in several case stories, and the selection criteria for further analysis of the cases presented here. This consultation process took place when most of the data were gathered and transcribed, and continued when the research report was written. This is known in the literature as 'peer debriefing'12 and helps to identify blind spots.

In the next three sections we describe the normative expectations of the women with MS.

\section{Ann}

Ann is a sportive looking woman in her thirties who has had MS for more then seventeen years. Ann presents herself as someone who has learned to live with MS. She talks in terms of 'decisions' she has made and makes - as if she is fully in control - and emphasizes the importance of being able to have freedom of choice. Ann states, for example, that it is very important for her to choose and decide what she likes. In her words: 'I will not do the things that are giving me no energy, that are drowning me.' She also emphasizes that she has taken the initiative to select her own caregivers. When she heard the diagnosis she left her neurologist and GP and went to search for new ones. She explains: 'I thought if I have to live with MS then I have to have caregivers whom I can live with.'

Ann found health care professionals whom she appreciates and with whom she can work together in a more or less horizontal relationship. She knew what she was looking for - people she could trust - and was well aware of her own needs. Ann also knows how to communicate her wishes ('I am capable of formulating my need for help.') and considers this part of her responsibility in the communication with professionals. Making deliberate choices and articulating needs are important elements of how Ann sees herself.

For quite some time Ann found satisfaction in becoming an active member of the Dutch Multiple Sclerosis Association (MSVN), but recently she is more critical of her voluntary work: 'Yes, of course, I got many compliments, but you cannot buy your bread with compliments.' What frustrates her is the fact that she doesn't have a professional career. Ann lost her job at the age of 28 years when she was diagnosed with MS. In those days in the Netherlands it was generally accepted that MS meant getting on insurance. Reintegration was not considered to be part of the treatment. This was a good solution for her employer, but it turned out to be a disaster for Ann. She found an alternative in her voluntary work for the MSVN, but discovered later on that her identity entails more than being a woman with MS: 'I am not solely an MS patient, I am also Ann who wants to do other things in life, in my spare time. I do not always want to be involved with MS; that is just a part of me.'

Ann's narrative of identity is thus built around becoming a professional woman again. She wants to be recognized by others as a professional, and not solely as an MS patient. Finding an appropriate job is, however, complicated. Ann compares it with a 'real crusade.' It is here that she expects support from others, among them employers: 'I need support from employers for this part in my life ... I also need others to support me. Contacts, networks, information, institutions, and whatever is needed.'

In her narrative of identity Ann envisions herself as a professional woman, but she readily acknowledges her vulnerability as an MS patient. This vulnerability is not only related to work, in other domains of life she also encounters problems. Ann's narrative of identity creates normative expectations towards herself and others. Ann takes on a lot of responsibility for her own health and welfare. She is the one who makes decisions, who is in charge. What she is able to do herself, she will take on. Yet, there are parts in life that she cannot completely control, and where she expects acknowledgement, help and support from others, especially from employers. Employers and others, however, have difficulties in identifying Ann as someone who requires support to realize her identity as a professional woman. It is the 
clash between the different narratives of identity that creates tensions between Ann and others.

\section{Kathy}

Kathy is in her forties and was diagnosed with MS more than twenty years ago. She lives alone in the northern part of the Netherlands. At home she is mobile without using equipment. Outside her house Kathy uses a wheelchair or a booster. She makes use of domestic assistance.

When Kathy was diagnosed with MS she worked fulltime, but over a period of several years, she has gradually reduced her working hours. She now works two afternoons per week. Since the last two years Kathy has frequently been on sickness leave because her condition has worsened. Due to the spasticity in both hands and her fatigue she wonders whether or not she is able to continue her work. In Kathy's opinion work is important; it gives her status, a meaningful place in society. Recently Kathy experiences, however, problems as a result of her worsening condition. She even cannot maintain social contacts with friends and family: 'As a matter of fact the last two years I only visited my sister once in a while to drink a cup of coffee. So there is a fair chance I will lose my friends and family, and that isn't what I want either.' Kathy wonders what to do, and consults her GP.

Her GP is a bit resistant to respond to her needs. He perceives himself as a medical doctor focusing on clinical matters such as Kathy's blood pressure and does not know how to attend to other than strictly medical problems. He says: 'I always found it hard when she visited the practice. I do not have the slightest idea what she is expecting from me. Possibly I would be able to support or coach her, but with Kathy I find it difficult. I have a sense offeeling that she is looking for support, but again she expresses no clear need for care. Of course, we talk, but in fact you're doing nothing.' Notice that talking is not considered to be part of the job and identity of a medical doctor, according to Kathy's GP. So, he does not discuss her situation, but responds to her concerns with an advice. He thinks she should continue her work, that Kathy would have no social life anymore if she were to give up her job. In his words: 'She wants to stop working because of her fatigue, but that is so vague and subjective. I suggested her to continue working in order to maintain her social contacts.'

The solution offered by the GP is, however, not satisfying to Kathy, because it does not take into account how important relationships with family and friends are for her. Kathy: ' I wonder if he understands my problems adequately, that it is difficult for me to solve the problems, such as getting on with fatigue, and the problems I am facing with my job and maintaining social contacts with friends and family, on my own.' This quote illustrates that Kathy's disappointment refers to the inattentiveness of the GP to her need for understanding and support. She does not expect the ready-made solution her GP offers, but assistance in arriving at her own solutions based on a better understanding of her own situation.

A psychologist in a nearby rehabilitation centre is better able to attend to her expectations. The psychologist does not give an advice, but enables Kathy to come to see her situation differently by asking questions. Kathy remembers: 'At one time she said: "At what cost do you want to stay at work, to what extend is it realistic to stay at work?"' This simple question provoked Kathy to come to a different evaluation of her situation. The psychologist defines her role as being a midwife of the patients' understanding: 'If I see that someone with MS, like Kathy, has already quite a long time developed a mechanism in which she isn't able to understand her situation, I as a professional have the responsibility to make her understand her situation and her possibilities. It's a mutual task.' After several meetings with the psychologist, Kathy comes to the conclusion that maintaining contacts with friends and family is more important for her than continuing her job. So she decides that it is better to go on insurance. The psychologist enabled Kathy to reach a solution that is fine-tuned to Kathy's situation and identity.

\section{Jane}

Jane is in her fifties, unmarried, and lives in a one-person room in a nursing home. Lately she has suffered from various bacterial infections, some of which were nearly fatal. Now she mainly stays in bed with oxygen, a tube in her nose, a catheter and an antidecubitus mattress. She is able to drink from a special mug, but cannot put make-up on by herself, is not able to wash herself, and cannot move herself from one side to the other. She needs assistance and help for everything.

Jane was diagnosed with MS at the age of eighteen. The disease was progressive and soon she is confined to a wheelchair. During those years she was very angry, continuously wondering 'Why does this happen to me?' What troubled her most was that people were ignoring her because she was sitting in a wheelchair. She notices: 'I am perfectly able to talkfor myself.' Although she expects he would learn to cope with the situation, she loses her boyfriend. She also loses her job, although she manages to work as a bookkeeper in the first two years of her illness. In 1971 she goes on insurance. With the help of a home care nurse and specialized family help her mother looks after her for many years. 
Then a period starts in which she often stays in hospitals, undergoing all kinds of treatments and cures. In 1979 she is blind for one day and night. Immediately she calls her doctor at the local hospital. He ensures her she will be hospitalized if the situation lasts for more than several days. When the situation becomes urgent he, however, informs her he will do nothing. Jane no longer trusts him and decides to go to a neurosurgeon in an academic hospital. Jane thus presents herself as someone who knows what she wants and who is able to make decisions concerning her life. Jane's self-conceptualization creates certain expectations towards others, such as the wish to be taken seriously. Conflicts emerge when others identify her as docile, because she sits in a wheelchair. Yet, she has also satisfying reciprocal relationships with others; her mother, family members and recently the residents in the nursing home. She experiences moral support from these people.

Lately Jane needs extra assistance and help. She experiences a lot of misunderstanding among the nurses. They do not always understand when she is tired. She also misses respect and loving attention from the nurses. It is frustrating that she almost always has to wait for help. She compares it with the way she was treated at home: 'It is a matter of asking again and again, and that I can not cope with, because I wasn't used to that at home.' She also notices that nurses get irritated when she asks them, for example, to give her something she can't reach. Besides the lack of attentiveness to her needs Jane is also critical about the expertise of the health care professionals.

Jane is physically dependent, but does not act in a dependent way. She presents herself - in line with her story of who she was in the past - as being articulate and critical. Given her narrative of identity she expects support and help with her daily routine, but also wants acknowledgement as a person who gives direction to her life. The health care professionals do not perceive her in the way she sees herself. They identify her as overly demanding and troublesome. The nursing home doctor notices: 'The nurses get 'sick' of this patient. She is sucking all the energy out of them. They can't handle her.' The prime problem, according to the nursing-home doctor, is that Jane is actually a psychiatric patient: 'The problem isn't her MS, it's her psychiatric and behavioral problems. She needs a particular, more psychiatric approach and our nurses aren't trained for that.'

The staff identifies Jane as a very particular, troublesome person who requires special expertise ('This patient counts as a separate ward'). They do not see her as a credible knower, and have a hard time to treat her with respect and attention.
Jane does not understand this: 'There ain't no love anymore. They don't ask, are you okay? They just put you in bed. They don't look after you, anymore.' Jane compares the staff with her mother who took care of her and all the attention she always received at home. She cannot accept that these expectations are not realistic in a different context; she remains the same person after all. Jane is remarkable, because most patients in a nursing home get hospitalized and will adjust their expectations. The staff does not understand Jane's life history and how Jane became the person she is (somewhat spoiled and demanding). And they cannot see that despite of Jane's character and deviant and strange behavior, she still is a human being in need of some love and understanding. So, again we see how conflicting narratives of identity create problems between MS patients and their caregivers.

\section{Identity and relationships}

In this analysis we reflect on the above stories and on how the narratives of identity of these women differ from narratives that others use to understand and identity them, and how this creates tensions in the caring relationships.

Narratives of identity are complex interactions between self-conceptualizations and perceptions others use to identity us. Ann presents herself initially as being in charge of her life and illness. The autonomy and self-determination she enacts in relation with her caregivers does, however, not work in relation to her employers. This is another part of Ann's identity; she is also vulnerable and dependent on other human beings, information, and institutions. This narrative of identity creates the expectation that others will give her assistance and support, especially when it comes to finding a job and to realize her future identity as a professional woman. Ann experiences, however, that others do not identify her as being vulnerable. As a result, she does not receive the help she expects and needs. She continues her crusade in search for a job on her own.

Kathy presents herself as losing her independence. She has always worked, and has always been quite articulate about her needs. Recently she has taken the initiative to visit a rehabilitation centre. Autonomy has always been an important value in her life. Difficulties start when her condition gets worse. Then the coordination of work and social life becomes complicated. Kathy expects support and understanding from her GP which he is not able to offer, as he identifies himself as a medical doctor attending to medical problems. He perceives Kathy as someone who cannot make her own decisions, and expects she will be satisfied with his advice to continue work. She isn't, because this recommendation doesn't take into account the 
value she endows to her family and friends. It also disrespects her wish to jointly discuss her situation. She is not a client or consumer in need of information to make a decision on her own (quit or continue work), but sees herself as a person searching for a new balance and direction in life. She needs a guide rather than a paternalistic doctor. Her psychologist is better able to assist her by helping her to revalue her life, thus respecting her identity as an autonomous and intelligent woman at a cross road of her life. Notice that autonomy is not restricted to self-determination here, but encompassing the connection with and relations with others.

Jane also presents herself as being independent, articulate and critical. She is complaining about the quality of care, expressing her needs and standing up for herself. Autonomy has always been an important value in her life; Jane, for example, choses her own doctor, which can be seen as an example of self-determination. Conflicts emerge when others identify her as docile and dependent. In the nursing-home the nurses and doctor expect Jane to act uncomplaining and grateful. Her demanding nature and her quite articulate complaints are considered as troublesome. Having defined her once as a psychiatric patient with behavioral problems, makes is hard for the staff to see Jane as a credible and knowledgeable person and to treat her as a human being in need of respect and dignity. They try to negate and ignore her. Jane also isn't capable to change her expectations. So the conflicts remain unsolved. Again we see how conflicting narratives of identity create a clash of expectations.

While Ann experiences that others do not identify her as being vulnerable, Kathy and Jane experience that others are not able to see them as being credible knowers and autonomous persons who are perhaps psychically dependent, but morally capable to direct their lives. In all cases normative expectations are in conflict, which creates tensions in the patient-professional relationship. Only the relationship between Kathy and her psychologist offers an alternative; here we see how the match between normative expectations fosters a good (=deliberative and dialogical) caring relationship in which the patient flourishes. The psychologist notices that Kathy does not need an advice to one particular answer, but rather needs to revalue her situation and what counts in life. Simple questions (at what cost do you want to continue work?) help Kathy to come to a new understanding of what is really important at this particular moment in her life.

\section{Conclusion}

The three stories show that it is difficult to deal with changes accompanying MS. This is a well known fact of MS.
Our account shows that coping is especially complicated given the highly individual and personal nature of MS stories, and differentiating (expectations of) relations. Walker's moral epistemology offers an innovative methodology to understand caring relationships in terms of the coordination of normative expectations between patients and professionals. The tales of the women with MS show that tensed relationships occur as a result of conflicting normative expectations, grounded in conflicting narratives of identity. Sorting out normative expectations in order to reach a shared understanding of who is responsible to whom and for what, requires that professionals caring for people with MS listen to their stories. In stories patients express how they see themselves. Walker's theoretical perspective also helps professionals to understand the uniqueness of MS patients. The narratives show that although the women had a similar medical condition, the meaning they endowed to their situation was very different. Each story was unique. There is a tendency in health care to use protocols and standards. Our analysis shows that care recommendations must be tailored according to individual needs of patients.

The particular needs of patients can be understood through interaction and communication. Health care professionals caring for persons with MS should at least ask themselves the following questions: a) how do I identify the needs of my patient? and b) what responsibility do I have for this patient? In order to answer these questions, they should pay attention to the way patients see themselves. So, health care professionals should create a space for patients to develop and tell their stories. The standard-question "How are you?" should be redefined in terms of "Who are you?" Professionals should ask themselves who the person is, how this person sees him/herself and what kind of expectations this generates. Professionals have a special responsibility in this regard given the vulnerability and dependency of patients. Professionals are the ones who should elicit patients' expectations thereby showing that this information is a valuable and necessary contribution to their care. ${ }^{13}$

Furthermore, professionals should be aware and responsive to the fact that the expectations of similar groups of patients can be very different, as the stories of the women with MS show. People describe themselves in different ways; even one person can change his or her image of self during the illness process. Like Ann, who was initially satisfied with her role as spokesperson of MS patients, but later began to long for a professional career, which appeared to be a real fight. With her changing perspective Ann's expectations also changed. She wanted a flexible job and help from her doctor 
to find an employer. Kathy, on the other hand, always worked and wanted to continue despite her fatigue, but then came to realize that keeping family and friends was more important. She expected support from her GP; not in terms of taking the decision for her, but in deliberating about her situation. Jane, the third MS patient in this article, becomes physically so dependent of the nursing homes staff, that she is almost completely out of control. Yet, mentally she remains able to direct her life. These highly personal accounts illustrate that attuning to the changing needs of MS patients and their expectations (of relations) is not at all easy.

Listening and understanding are very important, but often hard to practice for health care professionals. Kathy's GP does not consider listening as part of his job. He wants to act and finds it very difficult to respond adequately to the uncertainty Kathy experiences. Although he senses that she is suffering, he is unable to create a space for her feelings of grief and powerlessness. The psychologist had a different approach, and did not suppress Kathy's feelings and emotions. Giving space to suffering implies that one deliberately refrains from acting. The focus shifts from instrumental values to the intrinsic values of attentiveness, being present and being related to the patient. ${ }^{1}$ This is hard to practice for those health care professionals who define their identity in terms of being an expert. Creating a space for emotions and feelings of patients requires that one redefines one's selfimage as a health care professional. Being a good health care professional is not only a matter of technical expertise, but includes the moral virtues of being there and listening, responding to and taking part in the life story of the patient as it unfolds.

\section{Disclosure}

The authors report no conflicts of interest in this work.

\section{References}

1. Tronto J. Moral Boundaries. New York: Routledge; 1993.

2. Walker MU. Moral Understandings. New York: Routledge; 1998.

3. Held V. The Ethics of Care - Personal, Political and Global. Oxford: Oxford University Press; 2006.

4. Verkerk M, Widdershoven G, editors. Over zorg gesproken, Wiens verantwoordelijkheid? [Talking about care, Whose responsibility?] NWO/Ethiek en beleid, Stichting Drukkerij C. Regenboog; 2005.

5. Kagan PN. Listening: Selected perspectives in theory and research, Nurs Sci Q. 2008;21:105-110.

6. Kraft GH. Rehabilitation still the only way to improve function in multiple sclerosis. Lancet. 1999;354:2016-2017.

7. Boeije HR, Duijnstee MS, Grypdonck MH, Pool A. Encountering the downward phase: biographical work in people with multiple sclerosis living at home. Soc Sci Med. 2002;55:81-893.

8. Rothman AA, Wagner EH. Chronic illness management: what is the role of primary care? Ann Intern Med. 2003;138(3):256-261.

9. Reissman CK. Narrative Analysis. Qualitative Research Methods Series, 30. Newbury Park: Sage Publications; 1993.

10. Lieblich A, Tuval-Mashiach R, Zilber T. Narrative analysis, Reading, analysis and interpretation, Thousand Oaks: Sage Publications; 1998.

11. Meadows LM, Morse JM. Constructing evidence within a qualitative project, In: Morse JM, Swanson JM, Kuzel AJ, editors. The Nature of Qualitative Evidence. Thousand Oaks: Sage Publications; 2001. p. 187-201.

12. Lincoln YS, Gube EG. Naturalistic Inquiry. Bevely Hills, CA: Sage Publications; 1985.

13. Oeseburg B, Abma TA. Care as a mutual endeavour. Med Health Care Philos. 2006;9:349-357. 
